\title{
Screening and Comprehensive Evaluation for SRBD, Performed by Dentists in Everyday Clinical Practice
}

\author{
S. Gradanska, V. Yordanov, M. Dzhinova \\ Students of Dental Medicine in Medical University of Varna
}

\begin{abstract}
Background: The role of the dentist in screening patients at risk for sleep disorders and treating those diagnosed with sleep apnea is well positioned. The purpose of this study is to introduce the methods of screening and detailed evaluation of the risk of developing sleep apnea in dental patients.

Methods: Methods of screening using questionnaires such as ESS, STOP-BANG test and other questions are presented in this study. Once it has been determined that a patient is at risk of sleep apnea, a trained dentist can and should perform a clinical recognition and must be acquainted with the clinical findings that may indicate the risk for sleep apnea. A detailed evaluation assessing wide variety of factors not only in the oral cavity, but also extraoral - the TMJ, muscles, the head and neck posture, the organs of upper airways aims to focus the dentist's attention to a possible higher risk 100 of sleep apnea.

Results: Studies have shown that when a dentist is properly trained to evaluate for a sleep disorder by methods of screening and clinical recognition, the chances of uncovering one rapidly increase.

Conclusions: Becoming aware of conditions involving the head and neck that may indicate an increased level of risk for sleep apnea and higher understanding of those conditions is essential for optimum patient care and may lead to improved quality of life for dental patients.
\end{abstract}

\section{Introduction}

The role of the dentist in modern medicine is expanding rapidly. Today it is proven that the overall health of the patient may be impacted by their dental health. The dental work should not only be associated with the trivial things, such as tooth restoration, root canal cleaning and dentures, but also with the management of some diseases. Today science has proven that periodontal disease can lead to cardiovascular problems and erectile dysfunction (3). As any other family physician dentists can and should identify a patient who is at risk for sleep apnea (4). However, this requires some degree of training- the dentist must be able to recognize the symptoms and clinical findings related to a sleep breathing disorder.

\section{Methods}

Applying simple and focused questions such as existing questionnaires (ESS, STOP-BANG) or adding questions to those used by the dentist when taking a health history can easily bring to light factors that increase the risk of SRBD. The dental specialist may use the Epworth Sleepiness Scale (ESS) or the STOP-BANG questionnaire. Table 1 shows the STOP-BANG questionnaire, where every letter stands for a question (5). 


\begin{tabular}{|l|l|}
\hline First Four Questions & Four Additional Questions \\
\hline S: snore loudly & B: body mass index $>28$ \\
\hline T: feel tired during the day & A: age $>50$ years \\
$\begin{array}{l}\text { O: observed/witnessed to haves } \\
\text { stopped breathing }\end{array}$ & $\begin{array}{l}\text { N: neck size: male }>43 \mathrm{~cm} \text {; } \\
\text { female }>40 \mathrm{~cm}\end{array}$ \\
$\begin{array}{l}\text { P: high blood pressure } \\
\text { Yes to two or more questions:at risk }\end{array}$ & $\begin{array}{l}\text { G: gender: are you a male } \\
\text { Yes to one or more: at risk }\end{array}$ \\
\hline
\end{tabular}

Table 1. STOP-BANG questionnaire for assessing factors, increasing the risk of sleep apnea.

The ESS contains similar questions, but the answers are given with a point system. At the end of the questionnaire, the sum of the points indicates the risk for an OSA. Assessing the risks of OSA can also happen with the addition of a few basic questions to the existing medical questionnaire: Do you have difficulty falling asleep or staying asleep? Do you snore? Are you frequently tired during the day? Are you aware or have you been told that you stop breathing during sleep? Is your sleep unrefreshing? Special emphasis should be directed toward headaches, cardiovascular disease, diabetes, asthma, allergy, neurocognitive difficulties and medication. Positive responses to these questions would indicate that further evaluation is needed. If a patient is found at risk for sleep disorder, it is important for the dentist to know what additional questions to ask to confirm this and how to properly refer the patient for more definitive care (6). Table 2 shows some of the clinical findings connected with SRBD. Aside from gathering medical history, the temporomandibular joints (TMJs) should be evaluated for joint sounds, joint tenderness or pain. The range of motion of the mandible should also be recorded. Muscle tenderness in the head and neck is often a component of TMD and may be related to brusixm (7). The masseter, sternocleidomastoid, temporal and lateral pterygoid muscles should be evaluated. All dentists are comfortable in evaluating the dental and supporting structures of the oral cavity. Dentists must assess for periodontal disease and loose teeth. The presence of dental caries also must be evaluated. The tongue also should be evaluated in terms of its position at rest in the mouth relative to the soft palate and the ability to view the oropharynx. This evaluation is reffered as the Mallampati score (Table 3), where I stands for a full view of the oropharynx and IV represents full obstructuion of the oropharynx, soft palate and uvula (8).

\begin{tabular}{|c|c|}
\hline Clinical Observation & Potential Rolationship \\
\hline \multicolumn{2}{|l|}{ Tongue } \\
\hline Coated & $\begin{array}{l}\text { At risk for gastroesophageal reflux } \\
\text { disease or mouth-breathing habit }\end{array}$ \\
\hline Enlarged & Increased tongue activity, OSA \\
\hline $\begin{array}{l}\text { Obstruct viow of oropharymx } \\
\text { (Mallampatiscore) }\end{array}$ & $\begin{array}{l}\text { I and II lower risk for OSA } \\
\text { IIt and N increased nisk for OSA }\end{array}$ \\
\hline \multicolumn{2}{|l|}{ Teeth and periodontal structures } \\
\hline Ginglval inflammation & Mouth-breather, poor oral hygiene \\
\hline Drymouth (xerostomia) & Mouth-breather, may be medication \\
\hline Tooth wear & May have sleep bruxism \\
\hline \multicolumn{2}{|l|}{ Alrway } \\
\hline Long slopping soft paiste & At risk for OSA \\
\hline Enlargad/swollen/olongatod uvula & Atriak for OSAsnoring \\
\hline \multicolumn{2}{|l|}{ Extracoral. } \\
\hline $\begin{array}{l}\text { Chapped lilps or cracking at the } \\
\text { comers }\end{array}$ & Inabelity to nose-breathe \\
\hline Poorlip seal & Chronic mouth-breather \\
\hline
\end{tabular}

Table 2. Clinical findings, that the dentist can assess, performing a detailed evaluation of the risks of OSA.

\begin{tabular}{|c|l|}
\hline Score & $\begin{array}{l}\text { What is observed with the tongue at rest } \\
\text { mouth wide open }\end{array}$ \\
\hline I & $\begin{array}{l}\text { Visualize the soft palate, uvula, tonsils and the } \\
\text { oropharynx }\end{array}$ \\
\hline II & $\begin{array}{l}\text { Visualize the soft palate, most of the uvula, } \\
\text { superior portion of the tonsils, not the } \\
\text { oropharynx }\end{array}$ \\
\hline III & $\begin{array}{l}\text { Can see the soft palate but not the uvula, } \\
\text { tonsils, or into the oropharynx }\end{array}$ \\
\hline IV & $\begin{array}{l}\text { Cannot see the soft palate or any structures } \\
\text { below this, can only see the hard palate }\end{array}$ \\
\hline
\end{tabular}

Table 3. Mallampati score for assessing the position and the mass of the tongue by the visibility of the tonsils and uvula.

One of the key elements related to a successful treatment involves the patient's ability to breathe through the nose. Many people have difficulty breathing, especially at night, which can lead to a mouth-breathing habit (9). A questionnaire to determine a patient's breathing problems at night is useful. One of the simple to use is the Nasal Obstruction Symptom Evaluation (NOSE) scale, presented at Figure 1. The NOSE scale includes 5 questions and asks the patient to rate their perception of nasal airway problems over the past month based on a scale of 0 to 4 ranging from no problem to a severe problem (10). Improvement of the nasal airway alone may have an impact on the ability to breathe more comfortably. Through reducing the nasal airway resistance, inspiratory drive can also be reduced, which may reduce snoring and improve apnea. 


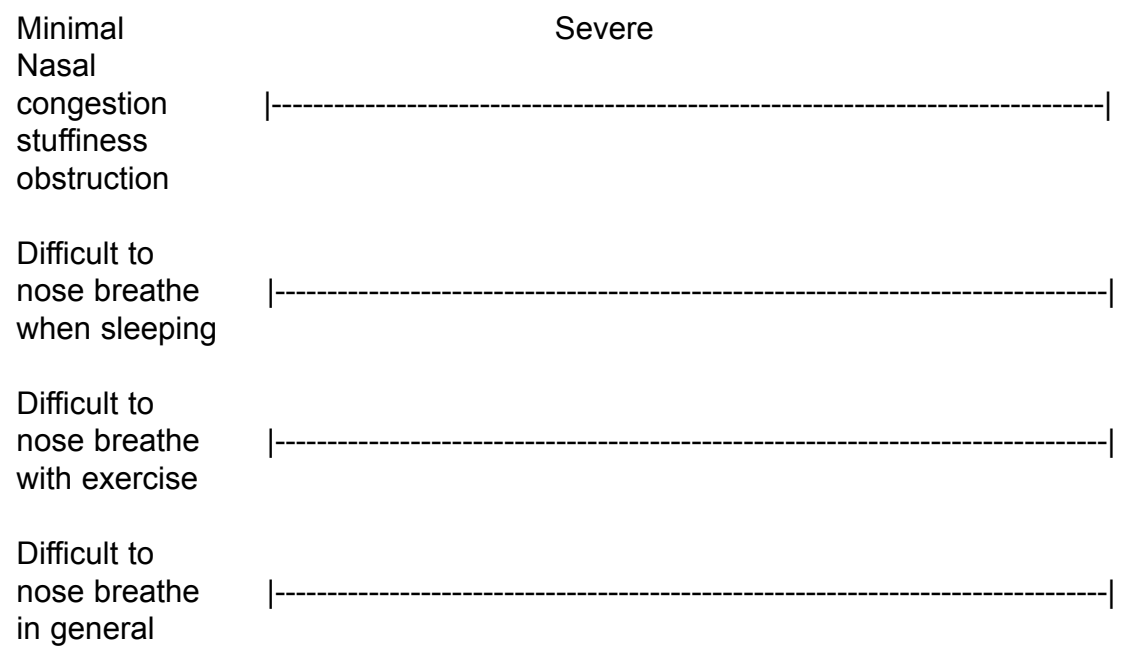

Figure 1. NOSE - Nasal Obstruction Symptom Evaluation scale

\section{Results}

Studies have shown that when a dentist is properly trained to evaluate for a sleep disorder by methods of screening and clinical recognition, the chances of uncovering one rapidly increase.

\section{Discussion}

The dentist can assume many different roles in the evaluation of patients for sleep-disordered breathing, from screening to active involment in management, often using an oral appliance.

\section{Conclusions}

Becoming aware of conditions involving the head and neck that may indicate an increased level of risk for sleep apnea and higher understanding of those conditions is essential for optimum patient care and may lead to improved quality of life for dental patients.

\section{References}

1. Attanasio R, Bailey D. Dental management of sleep disorders. 2009; 331-40.

2. Attanasio R, Bailey D. Dental management of sleep disorders. 2014;128-48.

3. Demmer RT, Desvarieux M. Periodontal infections and cardiovascular disease. JADA 2006; 145-205.

4. Schwarting S, Netzer NC. Sleep apnea for the dentist: political means and practical performance. Presented at Sleep Utah 2006, Annual Meeting of the APSS, Salt Lake City (UT), June 2006.

5. Silva GE, Vana KD, Goodwin JL, et al. Identification of patients with sleep disordered breathing: comparing the four-variable screening tool, STOP, STOP-Bang, and Epworth Sleepiness Scales. J Clin Sleep Med 2011; 467-72.

6. Bian H. Knowledge, opinions, and clinical experience of general practice dentists toward obstructive sleep apnea and oral appliances. Sleep Breat 2004; 85-90.

7. Tavel JG, Simons DG. Myofascial pain and dysfunction the trigger point manual. Baltimore (MD): Williams and Wilkins; 1983.

8. Nuckton TJ, Glidden DV, Browner WS, et al. Physical examination: Malampati score as an independent predictor of obstructive slep apnea. Sleep 2006; 903-8.

9. Pevernagie DA, De Meyer MM, Claeys S. Sleep, breathing and the nose. Sleep Med Rev 2005; 437-51.

10. Stewart MG, Witsell DL, Smith TL, et al. Development and validation of the nasal obstruction symptom evaluation (NOSE) scale. Otolaryngol Head Neck Surg 2004; 157-63.

11. Milkov, M. Combined approach to obstructive sleep apnea and snoring with intraoral and intranasal devices.- In: 2 nd Croatian Rhinologic Congress with International Participation. Zagreb, 23-25.II.2012. Proceedings, p. 54.

12. Milkov, M., F. Kirov. Proportion of patients with obstructive sleep apnoea among snorers in Bulgaria - a Varna obstructive sleep apnoea survey.- In: 21st Congress of the European Sleep Research Society. Paris, 4-8.IX.2012. Poster No P837.- J. Sleep Res., 21, 2012, Suppl. 1, p. 294.

13. Vicheva, D., M. Milkov. The use of bipolar radiofrequency-induced thermotherapy in allergic rhinitis in childhood.- In: 11th International Congress of the European Society of Pediatric Otorhinolaryngology (ESPO). Pediatric Otorhinolaryngology: From experience-based to evidence-based practice. Amsterdam, 20-23.V.2012. Abstracts book, p. 163.

14. Vicheva, D., M. Milkov. Postnasal drip syndrome in children.- In: 11th International Congress of the European Society of Pediatric Otorhinolaryngology (ESPO). Pediatric Otorhinolaryngology: From experience-based to evidence-based practice. Amsterdam, 20-23.V.2012. Abstracts book, p. 257.

15. Milkov, M., T. Tonchev, P. Nedev, F. Kirov, H. Madjova. International scientific communications in sleep apnea-related quality of life.- Sleep Medicine, 14S, 2013, e208-e209. 